\title{
Physical activity, diet and skeletal health
}

\author{
Francesco Branca* \\ National Institute of Nutrition, Via Ardeatina, 546, IT-00179 Rome, Italy \\ Accepted 13 July 1999
}

\begin{abstract}
Diet and physical exercise concur in the determination of skeletal mass at the end of adolescence and in the conservation of it during adult life. The functional demand imposed on bone is a major determinant of its structural characteristics. Stress applied to a skeletal segment affects the geometry of the bone, the microarchitecture and the composition of the matrix. The stimulatory effect occurs when the skeleton is subjected to strains exceeding habitual skeletal loads, and the intensity of load is more important than the duration of the stimulus.

Physical activity leads to greater bone density in children and adolescents and, to a minor extent, in adults. Weight bearing activities, such as walking, have a greater effect than non weight bearing activities, such as cycling and swimming. Reduction of loads as in bed resting or in space flights leads to bone loss. Intense training may cause damage, promptly repaired, as in stress fractures observed in army recruits. Female athletes may experience oligo-amenorrhea, though they still have a positive bone balance.

There is an important interaction between the mechanical demands and the availability of nutrients to manufacture bone tissue. The increase in bone density in post-menopausal women is positively related to calcium intake when calcium supplementation is accompanied by exercise. When mechanical demands are low, such as during immobilisation, the intestinal calcium absorption is reduced. Calcium intake should also be analysed in the light of other dietary factors affecting the balance between absorption and excretion, and in combination with a number of other minerals, trace elements and bioactive substances with an impact on bone metabolism.
\end{abstract}

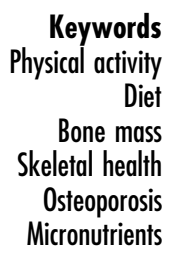

\section{Key messages}

A public health recommendation should be formulated as follows.

- Greater and more stable effects on bone mass are obtained if exercise is started early in life; active games and sport should be promoted from kindergarten and primary school.

- The skeleton should be subjected to high loads throughout life: lifestyle has to change; a specific programme, limited in time, is useful, but insufficient.

- Weight bearing exercise is required, such as walking, jogging, jumping, gymnastics, weight training.

- Physical activity is a safe practice; there is high tolerance limit before a negative effect appears.

- A good diet is necessary, rich in micronutrients; a diet rich in fruit and vegetables is perfectly safe and may possibly provide additional benefits, particularly in post-menopausal women.

\section{Introduction}

Osteoporosis is a systemic disease characterised by low bone mass and microarchitectural impairment of bone tissue, with a consequent increase in bone fragility and susceptibility to fracture. It is affecting an estimated 75 million people in Europe, the United States and Japan combined, including 1 in 3 postmenopausal women, the majority of elderly people and a substantial number of men ${ }^{1}$. The magnitude of this disorder will worsen by $60 \%$, unless suitable intervention can be devised, leading to about 650000 hip fractures in Europe ${ }^{2}$. Osteoporotic hip fractures can result in up to $20 \%$ excess mortality within one year. Additionally, up to $50 \%$ of patients will be disabled, half of them requiring long term nursing home care, while only one third fully recover from hip fracture. This entails a great burden on the health service, that in the UK was estimated to 750 million pound in $1994^{3}$.

The risk of an osteoporotic fracture in the elderly is compounded by the risk of fall and by the risk of fracture as a consequence of the fall. The former is influenced by many factors, such as the consumption of psychoactive drugs, dementia, depression and cognitive function, poor gait and muscle strength, poor postural stability and functional ability, dizziness and 
vestibular problems, poor functional ability and poor eyesight ${ }^{4}$. Fracture risk is affected by bone geometry, bone architecture, bone tissue material properties (i.e. the molecular arrangement of constituent mineral crystals, collagen crosslinking) and bone turnover ${ }^{5}$.

Exercise can certainly influence both the risk of fall and the risk of fracture. A comprehensive evaluation of the benefit of exercise on fracture prevention is provided by the study of Wickham et al. ${ }^{6}$. They found that elderly people in the low tertile of mobility had an odds ratio (OR) of 2 compared to those in the high tertile; those poorly active outdoors had a four times greater OR and those with little muscle strength had also a four times greater OR than those with intermediate or high muscle strength.

This article will discuss the main questions concerning the relationship between exercise and bone (when to do it, what type of exercise, for how long and how strenuously) and will examine the interactions between exercise and diet with the aim to provide public health recommendations on physical activity in relation to bone health.

\section{Which mechanisms mediate the effects of exercise on bone?}

The functional demand imposed on bone is a major determinant of its structural characteristics. Biomechanical studies indicate that stress applied to a skeletal segment affects the geometry of the bone, the microarchitecture and the composition of the matrix ${ }^{7}$. Animal studies demonstrated an increased thickness of lamellae with increased matrix deposition ${ }^{8}$ or an increased mineralisation ${ }^{9}$. The stimulatory effect occurs when the skeleton is subjected to strains exceeding habitual skeletal loads, and the intensity of load is more important than the duration of the stimulus. Thus, a minimum strain is required to produce an effect on bone. Conversely, a reduction of skeletal loads leads to a reduction of osteoblast activities and eventually to a negative bone balance. This adaptive modelling mechanism has been named "mechanostat"10.

Bone cells subjected to moderate mechanical stimulation respond with increased proliferation and matrix production. The strain imposed on bone activates the osteocytes, that start producing prostacyclin and osteoblasts that produce both prostacyclin and prostaglandin $\mathrm{E}_{2}$. A few minutes later, glucose-6-phosphate dehydrogenase activity increases in osteocytes, and in $24 \mathrm{~h}$ mRNA for growth factors is synthesised ${ }^{11}$.

\section{Does exercise have an effect at any age?}

Bone mass grows rapidly until the third decade, keeps more or less constant until the fifth decade in women and the sixth decade in men and then declines.
The effects of exercise have been shown both in cross-sectional and longitudinal studies. The interpretation of the former is confounded by a selection bias, particularly when different types of sport activities are compared $^{12}$.

This is why estimates obtained from longitudinal studies are more conservative. Cross-sectional studies show that individuals below the age of 50 participating in exercise programmes have on average an $8 \%$ greater bone mineral density (BMD) than age and sex matched individuals, while after the age of 50 the difference is only $6 \%$. Longitudinal studies show a $2 \%$ increase before age 50 and a $1 \%$ increase after $50^{12}$.

We have shown that children regularly carrying out moderate weight bearing physical activity have greater bone mass than age matched peers, possibly caused by decreased bone resorption. A group of 26 pre-pubertal boys (age $10 \pm 1.4$ years), were involved in a gymnastic training, spending about $3 \mathrm{hday}^{-1}$ in active games or sport and $3 \mathrm{~h}$ in sedentary activity, such as watching TV or reading. A second group of 10 children (age: $10.4 \pm$ 0.6 years) spent less than $1 \mathrm{hday}^{-1}$ in active games or sport and more than $4 \mathrm{~h}$ in sedentary activities. Total body Dual Energy X-ray Absorptiometry scans were performed and bone area (BA) and bone mineral content (BMC) calculated for the whole skeleton and for individual skeletal segments. The number of hours spent on weight-bearing activities (both organised sport and free play) was significantly correlated to the BMC at the level of the arms and the spine, after correction for BA, height and maturation stage. Each hour per day of weight bearing activity increased total bone density by $2 \%$.

If this level of activity is sustained long enough, greater peak bone mass is achieved, as demonstrated by the Amsterdam Growth and Health study, a 15-year longitudinal study, in which weight bearing physical activity (e.g. running, stair climbing) was correlated to the lumbar BMD at 27 years ${ }^{13}$.

\section{What is the most effective type of exercise?}

The absence of gravity, such as during space flights, or even prolonged bed resting, leads to bone loss, with a $0.3-0.4 \%$ loss of total bone calcium per month ${ }^{14}$. Paraplegic patients who do not recover walking have a $40 \%$ decrease in their BMC at the level of the pelvis and a $25 \%$ decrease at the legs after one year of immobilisation ${ }^{15}$. Histomorphometric studies show a $33 \%$ loss of trabecular bone in the six months following the trauma, followed by a stabilisation of the volume of trabecular bone ${ }^{16}$. Children with neuromuscular diseases, who experience a reduction in the loading history, also end up with a reduced bone crosssectional area ${ }^{17}$. It is not clear whether the negative bone balance is mainly the result of an increase in 
resorption or to a decrease in formation. In a study on volunteers the number of trabeculae decreased, the mean trabecular thickness increased, the active resorption surfaces stayed constant and the extent of the osteoid surface decreased ${ }^{18}$.

If inactivity is reversed, the damage can be limited. There is evidence that also passive mechanical loading in paraplegia can curb the loss of skeletal tissues ${ }^{19}$. Thus, rehabilitation of paraplegic patients is done with verticalisation implemented as early as possible. It still remains to be shown whether passive stimulation without a load also is able to delay bone loss.

A meta-analysis of several studies indicates that athletes have a $25 \%$ greater BMD than simply active people, and that active people have a $30 \%$ higher BMD compared to inactive people. Weight bearing activities, such as walking, have a greater effect than non weight bearing activities, such as cycling and swimming ${ }^{12}$.

A typical demonstration of the effect of mechanical load on bone mass is that on weight lifters. At the start of the training, they have BMD similar to that of normal controls; in as little as three weeks training weight lifters achieve a higher radial BMD, that is then maintained for the subsequent training. Weight lifters have a higher BMD throughout life, though it follows the same pattern of decline with age ${ }^{20}$. In early post-menopausal women, 9 months of weight training had a moderate effect on lumbar BMD $(+1.6 \%)$, compared to a decrease in controls $(-3.6 \%)^{21}$. In children, the time spent in weight bearing activities is correlated to BMD at all sites: radius, femoral neck, Ward's triangle, trochanter and lumbar ${ }^{22}$.

In a longitudinal study carried out in 22 young cyclists training for $10 \mathrm{~h}$ a week for over 2 years, the leg bone mineral content (BMC) was lower than controls ${ }^{23}$. This, however, may be a result of a selection bias. Smaller size individuals may perform better in this sport. Weight and height are in fact also lower and bone mass is also related to height. In children, biking is negatively correlated with BMD at femoral neck and Ward's triangle and swimming is not correlated at all ${ }^{24}$. In contrast, even arm pull may be important, as shown by the different cortical cross-sectional area of the humerus of male professional tennis players. Individuals in the upper quartile of forearm muscle strength have significantly greater diameter, significantly lower inner diameter, significantly greater cortical thickness and cortical area.

When the effect of an ordinary activity that everybody can perform is taken into account, such as walking, a moderate effect was observed. The whole body BMD was significantly higher in women walking more than 7.5 miles per week compared to that of women walking less than 1 mile per week ${ }^{24}$.

Jumping is a type of exercise that can be appropriate for postmenopausal women. After 6 months of a regular jumping programme ${ }^{25}$ observed an increase in trochanteric BMD of 3-4\%. In another study, stepping at low speed, jumping, skipping, marching and side stepping led to an increase in BMD at femoral neck and great trochanter after 1 year ${ }^{26}$.

Duration of training is probably a less important factor than load in determining the effects of exercise. In animals, strain magnitude is more important than number of strain cycles. In rats loaded with different times and loads, after 17 weeks experiment, increase in BMC was significantly larger than control in rats exercising $15 \mathrm{~min}$ with a $50 \mathrm{~g}$ load, while it was not significant in animals exercising $30 \mathrm{~min}$ without a load ${ }^{27}$. This is more similar to resistance (or weight) training than to endurance training.

\section{Are the effects of exercise permanent?}

According to the "mechanostat" theory, bone mass is always adapted to its mechanical needs. Therefore, if the habitual loading decreases, as during detraining, also bone mass should be brought back to its initial level. This theory was actually proven in a long term experiment, in which a first group of post-menopausal women exercised for 22 months; a second group trained for 17 months and then detrained and a third group did not participate in the programme. Both training groups increased their lumbar BMC by approximately 6\%. The second group, 13 months after detraining had a decrease back to baseline levels, while the control group had a $1 \%$ loss of lumbar BMC compared to baseline ${ }^{28}$.

However, in children the long term engagement in physical activity leads to an increase skeletal mass, that has then a protective effect throughout life.

\section{Are there individual differences in the response to exercise?}

There is an interindividual variability in the response to exercise, possibly in relation to genetic polymorphism. This was shown in individuals with different vitamin D receptor (VDR) alleles, in whom the mechanical stimulation led to different responses of the total BMC. The differences between the least responsive group and the highest responsive groups were in the order of $1 \%{ }^{29}$.

\section{Can excess or wrong exercise be dangerous for bone?}

There is no evidence of an adverse effect of normal levels of exercise on growth in children. Indeed, exercise can facilitate statural growth by stimulating growth hormone synthesis. In young female athletes, undertaking very intense aerobic exercise, oligomenorrhoea, 
amenorrhea, bone loss and stress fractures have been observed ${ }^{31-33}$. Approximately half of competitive female athletes experience oligomenorrhea or amenorrhea, compared to $5 \%$ in the general population. Intense training may cause damage, as in fatigue failure fractures observed in army recruits, that are however promptly repaired ${ }^{34}$.

In the elderly, the common idea that weight bearing exercise produces a negative effect on joints was not confirmed by experimental data, as long as the exercise programme is adequate to the fitness level of the individual $^{35}$. In women with low BMD inappropriate therapeutic exercise, such as spinal flexion (e.g. situps) or extension and flexion, may cause problems (increased wedge or compression fractures) and should be avoided ${ }^{36}$.

\section{Is there an interaction between exercise and diet?}

Twin studies indicate that $80 \%$ of the variance of bone density is determined by genetic factors ${ }^{22}$; other studies show that environmental factors, such as diet and physical activity, account for $20 \%$ of the variance each. This indicates that there is considerable overlap and interaction in the determinants of bone mass.

Several dietary factors have an influence on bone mass $^{37}$ and turnover ${ }^{38}$ : calcium, phosphorus, fluoride, zinc, copper, magnesium, manganese, sodium, potassium, vitamin $\mathrm{K}$, as well as bioactive substances such as phytoestrogens. Adequate quantities of such nutrients are probably necessary for exercise to be active on bone mass, though so far this interaction has been proven for calcium in humans and for zinc in animals.

Calcium intake varies widely among different world populations. Bone mineral density in adulthood has been related to a lifetime calcium intake ${ }^{39}$. However, other studies indicate that the dimensions, composition, and density of bones from communities with low calcium supplies are similar to those with higher calcium $^{40}$.

Supplementation trials carried out in children and adolescents have shown a positive effect on bone mass. An 18 month trial of calcium supplementation of 7 year old Hong King Chinese children, whose initial intake was approximately $500 \mathrm{mg} \mathrm{day}^{-1}$, with $300 \mathrm{mg} \mathrm{day}^{-1}$ elemental calcium, led to an increase of $4 \%$ in lumbar-spinal BMC and $2 \%$ in lumbar-spinal area ${ }^{41}$. A 3 year supplementation of the diet with $1000 \mathrm{mg}$ calcium citrate malate in twins aged 6-14 years showed that calcium enhanced the rate of increase in bone densiy ${ }^{42}$ and an 18 month trial in adolescent girls with $500 \mathrm{mg}$ /day calcium citrate also led to a significant increase in total bone density ${ }^{43}$.

In a longitudinal study in post-menopausal women, the group treated with exercise only had a decrease in the proximal forearm bone density; the group treated with exercise and calcium also had a decrease, though to a lesser extent; the group treated with exercise and oestrogens had instead an increase. A meta-analysis of sixteen studies carried out in post-menopausal women has shown that the increase in bone density was positively related to calcium intake when calcium supplementation was accompanied by a physical exercise program ${ }^{44}$. However, when mechanical demands are low, such as during immobilisation, the intestinal calcium absorption is reduced ${ }^{45}$.

In children, as long as calcium requirements are covered, exercise is more important as a determinant of bone mass. In our study in children, physical activity appeared to be more important than calcium intake in determining bone density, possibly because all the subjects had an adequate calcium intake. In the study by Welten et al. (1994) ${ }^{13}$, the daily intake of calcium was not correlated to peak bone mass at age 27, and in all subjects it met the Dutch Recommended Dietary Allowances of 900-1200 $\mathrm{mg} \mathrm{day}^{-1}$.

Zinc has an influence on estrogen and VDR; nucleic acid protein metabolism; collagen and mucopolisaccaride metabolism; activity of collagenase, carbonic anhydrase, alkaline phosphatase and prostaglandins ${ }^{46}$. In female rats strenuously exercising on a treadmill the length, weight, bone mineral content (BMC), and bone mineral density (BMD) of the femur was lower in animals receiving a normal diet, compared to those receiving a zinc supplemented $\operatorname{diet}^{47}$.

\section{Conclusions}

The effects of physical activity on bone mass can be summarised by looking at the criteria that the American College of Sports Medicine has set forth: (a) effects are localised, and only sites which are loaded by the exercise can respond (Specificity); (b) the training stimulus must exceed the normal loading experienced in everyday life (Overload); (c) any positive effects of increased activity will be lost if discontinued (Reversibility); (d) people with the lowest BMD at the start of the training will have the greatest capacity to improve BMD if expressed as a percentage of change (Initial values); (e) each person has an individual biological ceiling that determines the extent of a possible training effect (Diminishing returns) ${ }^{48}$.

Diet and physical exercise concur in the determination of skeletal mass at the end of adolescence and in the conservation of it during adult life. However, the greatest prevention potential is present early in life. At present, while the coverage of most nutrient requirements for optimal bone growth seems to be met in most European populations, the requirement for optimal physical activity is not. Children are engaged for an increasing amount of time in sedentary activities. In $1993,90 \%$ of $6-9$ year old Italian children spent $2 \mathrm{~h}$ a 
day watching TV, while only 16\% spent between 1 and $2 \mathrm{~h}$ walking and less than $10 \%$ practised sports ${ }^{49}$ ).

Individuals that in their young adulthood had BMD equal or above the $95^{\text {th }}$ centile, at the age of 80 have BMD $0.2 \mathrm{~g} \mathrm{~cm}^{-2}$ greater than individuals who had BMD equal or below the $5^{\text {th }}$ centile. This $25 \%$ difference in BMD exposes them to a $50 \%$ greater risk of fracture, that at 90 becomes a $100 \%$ greater risk of fracture ${ }^{50}$.

To what extent this $25 \%$ difference can be achieved by lifestyle changes is so far a matter of speculation. A population-based cross-sectional study showed that men having higher levels of physical activity at work or during leisure time had a greater BMD (up to 9\%) than less active individuals ${ }^{51}$, but a significant difference could not be shown in women. The same study did not show a difference according to the time spent watching TV or the means of transport to and from school or work. In another retrospective study, men more active in their leisure time had greater lumbar spine area (11\%) and femoral neck area (5\%), but men exposed to higher levels of occupational activities had lower BMD than men professionally less active ${ }^{52}$. The only long-term longitudinal study ${ }^{13}$ indicates that $9-17 \%$ of the variance in BMD at age 27 is determined by the time spent on weight bearing physical activities. However, these estimates do not take into account the interaction between physical activity, nutrition and genetic background and are therefore conservative.

\section{References}

1 Consensus Development Conference. Diagnosis, prophylaxis and treatment of osteoporosis. Am. J. Med. 1993; 94: $646-50$.

2 Cooper C, Campion G, Melton III LJ. Hip fractures in the elderly: a world-wide projection. Osteoporosis Int. 1992; 2: 285-89. (Abstract).

3 Rutherford OM. Bone density and physical activity. Proc. Nutr. Soc. 1997; 56: 967-75.

4 Grisso JA, Capezuti E, Schwartz A. Falls as risk factors for fractures. In: Marcus R, Feldman D, Kelsey J, eds., Osteoporosis. London: Academic Press, INC. 1996.

5 Slemenda CW, Johnston CC, Hui SL. Assessing fracture risk. In: Marcus R, Feldman D, Kelsey J, eds., Osteoporosis. London: Academic Press, INC, 1996.

6 Wickham CAC, Walsh K, Cooper C, Barker DJP, Margetts BM, Morris J, Bruce SA. Dietary calcium, physical activity and risk of hip fracture: a prospective study. Br. Med. J. 1989; 299: 889-91.

7 Carter DR, Van Der Meulen MC, Beaupre GS. Mechanical factors in bone growth and development. Bone 1996; 18(1 Suppl): 5 S-10S.

8 Tuukkanen J, Wallmar B, Jalovaara P, Takala T, Sjogren S, Vaananen K. Changes induced in growing rat bone by immobilization and remobilization. Bone 1991; 12: 1138.

9 Yeh JK, Liu CC, Aloia JF. Additive effect of treadmill exercise and 17 beta-estradiol replacement on prevention of tibial bone loss in adult ovariectomized rat. J. Bone Min. Res. 1993; 8(6): $677-83$.

10 Frost HM. The mechanostat: a proposed pathogenic mechanism of osteoporosis and bone mass effects on mechanical and non mechanical agents. Bone Miner. 1987; 2: $73-85$.

11 Lanyon LE. Control of bone architecture by functional load bearing. J. Bone Miner. Res. 1992; 7: S369-75.

12 Forwood MR, Burr DB. Physical activity and bone mass: exercises in futility. Bone Miner. 1993; 21: 89-112.

13 Welten DC, Kemper HCG, Post GB, Van Mechelen W, Twisk J, Lips P, Teule GJ. Weight-bearing activity during youth is a more important factor for peak bone mass than calcium intake. J. Bone Miner. Res. 1994; 9: 1089-96.

14 Vogel JM, White MW. Bone mineral changes: the second manned Skylab mission. Aviation, Space and Environmental Medicine 1976; 47: 396-400.

15 Wilmet E, Ismail AA, Heilporn A, Weraeds D, Bergmann P. Longitudinal study of the bone mineral content and of soft tissue composition after spinal cord section. Paraplegia 1995; 33: 674-7.

16 Uebelhart D, Demiaux-Domenech B, Roth M, Chantraine A. Bone metabolism in spinal cord injured individuals and in others who have prolonged immobilisation. A review. Paraplegia. 1995; 33: 669-73.

17 Rodriguez JI, Garcia-Alix A, Palacios J, Paniagua R. Changes in long bones due to fetal immobility caused by neuromuscular disease. J. Bone Joint Surg. 1988; 70A: 1052-60.

18 Palle S, Vico L, Bourrin S, Alexandre C. Bone tissue response to four-month antiorthostatic bedrest: a bone histomorphometric study. Calcif. Tissue Int. 1992; 51(3): 189-94.

19 Goemaere S, Van Laere M, De Neve P, Kaufman JM. Bone mineral status in paraplegic patients who do or do not perform standind. Osteoporos. Int. 1994; 4: 138-43.

20 Karlsson MK, Johnell O, Obrant KJ. Bone mineral density in weight lifters. 1993; 52: 212-15.

21 Pruitt LA, Jackson RD, Bartels RL, Lehnhard HJ. Weighttraining effects on bone mineral density in early postmenopausal women. J. Bone Miner. Res. 1992; 7: 179-85.

22 Slemenda CW, Miller JZ, Hui SL, Reister TK, Johnston CC. Role of physical activity in the development of skeletal mass in children. J. Bone Min. Res. 1991; 6(1): 1227-33.

23 Rico H, Revilla M, Hernandez ER, Gomez-Castresana F, Villa LF. Bone mineral content and body composition in postpubertal cyclist boys. Bone 1993 Mar-Apr; 14(2): 93-5.

24 Krall EA, Dawson-Hughes B. Walking is related to bone density and rates of bone loss. Am. J. Med. 1994; 96: 20-6.

25 Bassey EJ, Ramsdale SJ. Increase in femoral bone density in young women following high impact exercise. Osteop. Internat. 1994; 4: 2-75.

26 Welsh L, Rutherford OM. Hip bone mineral density is improved by high-impact exercise in post-enopausal women and men over 50 years. Eur. J. Appl. Physiol. 1996; 74: 511-17.

27 van der Wiel HE, Lips P, Graafmans WC, Danielsen CC, Nauta J, van Lingen A, Mosekilde L. Additional weightbearing during exercise is more important than duration of exercise for anabolic stimulus of bone: a study of running exercise in female rats. Bone 1995; 16: 73-80.

28 Dalsky GP, Stocke KS, Ehsani AA, Slatpolsky E, Lee CW, Birge SJ. Weight-bearing exercise training and lumbar bone mineral content in postmenopausal women. Ann. Int. Med. 1988; 108: 824-28.

29 Järvinen TLN, Järvinen TAH, Sievanen H, Heinonen A, Tanner M, Huang X-H, Nenonen A, Isola JJ, Jarvinen M, Kanus P. Vitamin D receptor alleles and bone's response to physical activity. Calcif. Tissue Int. 1998; 62: 413-17.

30 Borer KT. The effects of exercise on growth. Sports Med. 1995 Dec; 20(6): 375-97.

31 Drinkwater BL, Nilson $\mathrm{K}$, Chesnut $\mathrm{CH}$, Bremner WJ, Shainholtz S, Southworth MB. N. Eng. J. Med. 1984; 311: 277-81.

32 Myburgh KH, Hutchins J, Fataar AB, Hough SF, Noakes TD. 
Low bone density is an etiologic factor for stress fractures in athletes. Ann. Int. Med. 1990; 113: 754-59.

33 Wilson JH, Wolman RL. Osteoporosis and fracture complications in an amenorrhoeic athlete. BrJ Rheumatol 1994; 33: $480-1$.

34 Pester S, Smith PC. Stress fractures in the lower extremities of soldiers in basic training. Orthop. Rev. 1992; 21(3): 297-303.

35 Coleman EA, Buchner DM, Cress ME, Chan BK, de Lateur BJ. The relationship of joint symptoms with exercise performance in older adults. J. Am. Geriatr. Soc. 1996; Jan; 44(1): 14-21.

36 Sinaki M, Mikkelsen BA. Postmenopausal spinal osteoporosis: flexion versus extension exercises. Arch. Phys. Med. Rehabil. 1984 Oct; 65(10): 593-6.

37 Reid DM, New SA. Nutritional influences on bone mass. Proc. Nutr. Soc. 1997; 56: 977-87.

38 Robins SP, New SA. Markers of bone turnover in relation to bone health. Proc. Nutr. Soc. 1997; 56: 903-14.

39 Matkovic V. Calcium metabolism and calcium requirements during skeletal modelling and consolidation. Am. J. Clin. Nutr. 1991; 54: 245S-60S.

40 Walker ARP. The human requirement of calcium: should low intakes be supplemented? Am J Clin Nutr 1972; 25: 518-30.

41 Lloyd T, Andon MB, Rollings N, et al. Calcium supplementation and bone mineral density in adolescent girls. JAMA 1993; 270: 841-44.

42 Johnston CC, Miller JZ, Slemenda CW, et al. Calcium supplementation and increases in bone mineral density in children. N. Engl. J. Med. 1992; 327: 82-7.

43 Lee WTK, Leung SSF, Leung DMY, Tsang HSY, Lau J, Cheng JCY. A randomized double-blind controlled calcium supplementation trial, and bone and height acquisition in children. Br. J. Nutr. 1995; 74: 125-39.

44 Specker BL. Evidence for an interaction between calcium intake and physical activity on changes in bone mineral density. J. Bone Min. Res. 1996; 11: 1539-44.

45 Yeh JK, Aloia JF. Effect of physical activity on calciotropic hormones and calcium balance in rats. Am. J. Physiol. 1990; 258: E263-8.

46 Wallwork JC, Sandstead HH. Zinc. In: D.J. Simmons, ed. Nutrition and bone development. New York: Oxford University Press, 1990.

47 Seco C, Revilla M, Hernandez ER, Gervas J, Gonzalez-Riola J, Villa LF, Rico H. Effects of zinc supplementation on vertebral and femoral bone mass in rats on strenuous treadmill training exercise. J. Bone Miner. Res. 1998 Mar; 13(3): 508-12.

48 American College of Sports Medicine. ACSM position stand on osteoporosis and exercise. Medicine and Science in Sports and Exercise 1995; 27: I-VII.

49 ISTAT. Indagine Multiscopo sulle famiglie, Anni 1987-1991. No. 4. L'uso del tempo in Italia. Roma: Istituto di Statistica, 1993.

50 Riggs BL, Melton LJ. The prevention and treatment of osteoporosis. N. Engl. J. Med. 1992; 27;327(9): 620-7.

51 Duppe H, Gardsell P, Johnell O, Nilsson BE, Ringsberg K. Bone mineral density, muscle strength and physical activity. Acta Orthop. Scand. 1997; 68: 97-103.

52 Brahm H, Malmin H, Michaelsson K, Strom H, Ljunghall S Relationships between bone mass measurements and lifetime physical actvity in a Swedish population. Calcif. Tissue Int. 1998; 62: 400-12. 